\title{
ANALISIS PEMANFAATAN PERTOLONGAN PERSALINAN NON TENAGA KESEHATAN DI KABUPATEN KOLAKA TIMUR (Studi Kasus di Puskesmas Ueesi)
}

\author{
Muh. Ridha Setiawan Salam*,Sutopo Patria Jati**, Sri Achadi Nugraheni** \\ *Alumni Magister Ilmu Kesehatan Masyarakat Universitas Diponegoro, **Staf Pengajar Program \\ Magister Ilmu Kesehatan Masyarakat Universitas Diponegoro \\ Email: onethonk07@gmail.com
}

\section{ABSTRACT}

Traditional services or service by dukun is a phenomenon of community tradition that needs to be evaluated, especially related to birth assisstance. The scope of delivery by health workers was still low of $68 \%$ in 2016.This was qualitative research with phenomenological approach. The subjects of this study were maternal mothers who gave birth within the last 1 (one) year selected from the highland region and lowland region in the Uesesi Puskesmas area. Data were collected by in-depth interview techniques. Processing and data analysis using content analysis. Results showed that there were predisposition factors, enabling factors and reinforcing factors which influenced the behavior. The predisposition factors were 1) the informant is able to explain about healthy labor but unable to explain the safe delivery 2) The informant is still more inclined to the service of dukun maternity 3) The high trust of informant to the dukun maternity. The enabling factors were 1) access to utilize the service of dukun maternity is easy because dukun apply method "pick up ball" 2) Cost of labor can be reached by informant. The reinforcing factors were family and some toma support while some other toma leads to no longer utilize the services of dukun maternity.It is advisable to develop strategies to minimize the number of shamans who perform delivery services, provide education and understanding to the community about
\end{abstract}

delivery by health personnel, and to update and conduct regular meetings on issues related to midwifery science so as to create a quality profession.

Keywords: Delivery Health Service; NonHealth Personnel; Maternity

\section{PENDAHULUAN}

Di Kabupaten Kolaka Timur pada tahun 2016 masih terdapat 6 (enam) puskesmas dimana cakupan pertolongan persalinan oleh tenaga kesehatan belum mencapai target yakni Puskesmas Ueeesi, Puskesmas Sanggona, Puskesmas Lambandia, Puskesmas Aere, Puskesmas Dangia dan Puskesmas Poli-Polia. Cakupan Persalinan oleh tenaga kesehatan di Puskesmas Ueesi pada Tahun 2016 yakni sebesar $\quad 68 \% .{ }^{1}$ Rendahnya cakupan pertolongan persalinan oleh tenaga di Puskesmas mengindikasikan bahwa tingkat pemanfaatan pertolongan persalinan oleh tenaga kesehatan di wilayah tersebut masih tergolong rendah.

\section{METODE PENELITIAN}

Rancangan penelitian ini menggunakan rancangan kualitatif yang disajikan secara deskriptif eksploratif melalui observasi dan wawancara mendalam. Penelitian dilaksanakan pada bulan Februari sampai dengan April tahun 2017 yang berlokasi di Puskesmas Ueesi Kabupaten Kolaka Timur Provinsi Sulawesi Tenggara. 
Pengumpulan data dengan cara wawancara mendalam (indept interview), pengolahan dan analisis data dengan cara pengumpulan data, reduksi, verifikasi, dan penyajian. Observasi dengan pengamatan langsung dan telaah dokumen.

Subjek penelitian ini yakniibu bersalin yang melahirkan dalam kurunwaktu 1 (satu) tahun terakhir yang dipilihdari wilayah dataran tinggi 4 orang dandataran rendah 4 orang di Wilayah Kerja Puskesmas Ueesi. Variabel yang diteliti yaitu faktor predisposisi ( pengetahuan, sikap dan kepercayaan), faktor enabling dan faktor reinforcing.

\section{HASIL DAN PEMBAHASAN}

\section{Faktor Predisposing (predisposisi)}

a. Pengetahuan

Dalam hal kaitannya pemahaman informan terhadap jasa pelayanan non tenaga kesehatan bahwasanya hampir semua informan memiliki pemahaman yang cukup tentang persalinan menggunakan jasa non tenaga kesehatan. Untuk informan yang berada di wilayah dataran tinggi, semua informan memiliki pengetahuan yang baik tentang jenis persalinan yang sehat, namun ketika peneliti menanyakan dengan "bagaimana dengan persalinan yang aman ?" sebagian besar informan tidakmampu mendefinisikan dan adanya salah satu informan yang hanya terdiam dan tersenyum ketika pertanyaan kedua ditanyakan yakni tentang persalinan yang aman. Sebagaimana kutipan wawancara berikut ini:

$$
\begin{aligned}
& \text { "Persalinan yang sehat itu kalo kita bisa } \\
& \text { melahirkan normal" } \\
& \text { "Orang melahirkan toh? Yang bisa keluar } \\
& \text { bayinya tanpa cacat" } \\
& \text { "Sehat bayinya, bagus keluarnya trus sehat } \\
& \text { juga ibunya toh" }
\end{aligned}
$$

Kemudian peneliti juga melakukan wawancara kepada ibu bersalin, diperoleh bahwa untuk informan yang berada pada wilayah dataran tinggi masih adanyajawabandari informan yang berbelit-belit dan membuat informan agak sedikit bingung untuk menafsirkan. Setelah diadakan diskusi bersama penerjemah bahasa lokal maka dapat disimpulkan dalam kutipan hasil wawancara:

"Itu ina tetangga ji, pasti mi iya kita tau siapa dia siapa keluarganya"

"Itu ina sudah dia mi menunggu kalo sudah kita rasa sakit sakit mi kita punya perut baru pintar tare kepala bayi"

Informan yang berada di wilayah dataran rendah, diperolehnya informasi bahwa pemahaman informan terhadap dukun masih bersifat general / umum.. Sebagaimana kutipan hasil wawancara berikut :

"Dukun itu orang yang ada bantu kita kalo misalnya nda ada bidan dirumahnya"

"Sudah itu mi yang biasa bantu kita kita kalo ada mau melahirkan kasian"

(IU.R4)

Selanjutnya peneliti menggali informasi seputar pemahaman informan tentang persalinan sebaiknya ditolong oleh siapa. Informan yang berada pada wilayah dataran tinggi semua mengatakan bahwa persalinan yang dilakukan selama ini tidak bersama Bidan melainkan dukun bersalin. Doktrin masyarakat terhadap dukun cukup tinggi, sebagaimana kutipan hasil wawancara dibawah ini :

"Mamanya fajar jago itu.."

"Inae inggiro opa namanya? (bertanya kepada suami) maa itu mi ibu dukun bisa juga.."

(IU.T2)

Informan yang berada di wilayah dataran rendah memiiki pandangan yang berbeda. Hasil wawancara dapat dilihat pada

"Sebenarnya sama orang kesehatan, tapi mau diapa juga begini keadaanya"

"Sa sudah baku cocok mi mungkin kalo sama i Tina" 
Konteks pemahaman informan terhadap kelebihan dari seorang dukun bersalin memiliki ekspektasi yang cukup baik. Kelebihan yang dimilki oleh seorang dukun lebih kepada sifat ketelatenan dan komunikasi yang dibangun serta pendekatan persuasif sangat baik sehingga membuat informan nyaman dengan situasi tersebut. Berikut hasil wawancara kepada informan utama:

"Dia tunggui saya sampai selesai da bersihkan darah darahnya anakku."

"Sabar hae pak, tidak banyak bicaranya."

"Apa di pak, nda ada ji sebenarnya hanya itu ji biar jam berapa kita butuh da datang juga"

(IU.R3)

Selanjutnya peneliti melakukan wawancara terkait dengan pemahaman ibu bersalin terhadap definisi layanan persalinan. Sehingga diperolehnya informasi dari semua informan tidak mampu menjelaskan definisi layanan persalinan dukun bersalin dengan benar. Sebagaimana kutipan hasil wawancara berikut :

"Bantu melahirkan pak?"

"Ada orang melahirkan trus dibantu sama dukun."

"Dukun bantu kita melahirkan."

Pada sisi perawatan dan pelayanan yang diberikan dukun dalam pertolongan. Semua informan mampu menjelaskan tentang jenis pelayanan yang sering diberikan dukun bersalin baik itu saat persalinan dan setelah melahirkan. Akan tetapi adanya 1 (satu) orang informan yang mengatakan jenis pelayanan bidan dan dukun sama. Berikut kutipan hasil wawancara bersama informan utama:

"Pokonya dari awal sampe bersih-bersih kamar semua mi”

"Da bisa raba-raba itu perut"

"Hampir sama ji sama bu bidan tapi nda ada alatnya dia"

(IU.R1)
Setelah jenis pelayanan dukun bersalin diuraikan diatas selanjutnya peneliti menggali informasi perihal ada tidaknya kerugian yang timbul akibat memanfaatkan jasa non tenaga kesehatan dan mayoritas informan mengatakan tidak adanya kerugian yang diderita sekalipun dari sisi finansial ibu bersalin dan keluarga. Berikut kutipan wawancara informan utama:

"Nda ada orang bu bidan disini pak, jadi kita ndatau kasian rugi apa tidak"

"Sebenarnya kalau rugi tidak pak"

Selain dari wawancara kepada informan utama, peneliti juga melakukan wawancara kepada informan triangulasi untuk membandingkan hasil wawancara. Ada beberapa hal yang di pertegas oleh informan triangulasi bahwa masyarakat Kecamatan Ueesi pada umumnya masih memiliki pemahaman yang cukup terhadap respon persalinan yang sehat. Hal ini diungkapkan oleh informan triangulasi Bidan Koordinator Puskesmas dalam kutipan wawancara berikut:

Baik, dapat saya jelasakan bahwa mayoritas penduduk disni memiliki pendidikan rata-rata tamat SMA, dari pendidikan ini dapat kita gambarkan kalau memang pemahaman masyarakat dapat di masuki oleh pemikiran yang apatis, dan terutama yang berada di desa/kampung pelosok terlebih dengan modernisasi saat ini yang belum sampai kesana

(IT.BK)

Informasi seputar kesehatan hanya dapat diperoleh masyarakat melalui wadah / kegiatan Posyandu. Hal ini dijelaskan oleh informan triangulasi Bidan Koordinator pada kutipan wawancara berikut :

"Iye, biasanya kami lakukan pada saat posyandu di beberapa Desa di wilayah kerja Puskesmas kami.."

(IT.BK) 
Dari beberapa uraian di atas dapat disimpulkan bahwa pemahaman masyarakat terhadap pelayanan kesehatan masih dapat dikategorikan cukup baik, hal ini dibuktikan dengan beberapa kutipan wawancara kepada informan utama yang sebagian besar mengatakan bahwa persalinan yang sehat yakni persalinan yang ibu dan bayinya dalam kondisi normal.Beberapa faktor yang mempengaruhi tingginya pemahaman ibu tentang persalinan non tenaga kesehatan dikarenakan bulin telah dan sering memanfaatkan jasa non tenaga kesehatan, dikarenakan bulin berada diwilayah dataran tinggi dan rendah yang tidak memiliki Bidan sehingga alur penyampaian informasi sering terhambat, tentunya hal ini juga di pengaruhi oleh pekerjaan informan yakni mayoritas merupakan petani dan ibu rumah tangga yang sehari-harinya menghabiskan waktu dikebun dan dirumah. Secara umum pendidikan yang rendah turut andil dalam pengembagan ilmu pengetahuan. Menurut teori, pengetahuan adalah akumulasi dari pengalaman yang didapat melalui penginderaan. ${ }^{2} \mathrm{Hal}$ ini sangat penting mengingat pengetahuan akan kesehatan dalam hal ini pengetahuan tentang persalinan yang bersih dan aman pada tenaga kesehatan adalah salah satu unsur penting untuk membentuk prilaku kesehatan. Hasil penelitian tim Imppact di Daerah Serang dan Pandeglang Indonesia menyimpulkan bahwa pengetahuan tentang kesehatan yang tidak memadai menyebabkan kaum ibu enggan memanfaatkan layanan pemeriksaan dan persalinan tenaga kesehatan, sehingga terjadi kegagalan penanganan pada kasus-kasus komplikasi yang berujung pada kematian ibu dan anak. $^{3}$

b. Sikap

Berdasarkan data dari Seksi Kesehatan Ibu dan Anak Dinas Kesehatan Kabupaten Kolaka Timur, dapat dilihat bahwa laporan Puskesmas Ueesi terhadap cakupan K1 sebesar 66 atau 87\% dan K4 sebesar 54 atau $71 \%$ kunjungan selama tahun 2016, namun pada saat persalinan ibu lebih memilih untuk beralih ke pelayanan non tenaga kesehatan. Hal ini dapat terlihat pula cakupan persalinan tenaga kesehatan yang sangat rendah yakni sebesar $68 \%$ dan menempatkan Puskesmas Ueesi sebagai Puskesmas dengan cakupan persalinan paling rendah di Kabupaten Kolaka Timur. Adapun kutipan wawancara informan utama dapat dilihat di bawah ini :

"Kalo periksa itu pernah ji sama Bidan skali kali.."

"Pernah juga sama Bidan klo puskesmas pernah juga.."

(IU.R4)

Sedangkan pada saat persalinan ibu lebih memilih ditolong oleh dukun bersalin. Hal ini dikarenakan sejauh ibu melahirkan bersama dukun bersalin, tidak menemukan kendala yang begitu berarti, dan semua dalam kondisi baik pada saat persalinan. Berikut petikan wawancara :

"Bagus inae nda jauh beda ji sama Bidan.."

"Lancar lancar ji, hiii semoga kasian nda kenapa kenapa kalo da tolong ki.."

(IU.R2)

Sekalipun adanya informan yang merasakan resiko tersebut tapi sudah menjadi pilihan bagi ibu bersalin untuk memanfaatkan jasa non tenaga kesehatan.

"Kalo saya sebenarnya iye pak hanya kan dimana Bidan dimana kita pwa.."

"Kalo sama Bidan memang aman toh pak tapi itu mi lagi.."

(IU.R2)

Dalam teknik dan manajemen perawatan yang dimiliki oleh non tenaga kesehatan tentunya ada beberapa metode yang tidak dimiliki oleh Bidan. Hal ini dapat dilihat dalam kutipan wawancara berikut : 
"... Waktu sa melahirkan da rawat sampe da rasa kita sehat."

"Kalo saya bagus ji tawwa karena da sudah biasa mi,da tunggui betul kita begadang samasama mi bapaknya disitu, pokoknya kayak mamanya mi kita"

(IU.R1)

Beberapa kutipan wawancara informan utama diatas dapat disimpulkan bahwa adanya keseimbangan antara ilmu tradisional dan ilmu medis. Ilmu tradisional yang diterapkan oleh dukun lebih kepada bagaimana dukun mampu memandikan ibu bersalin dan bayi secara langsung dengan menggunakan ramuan-ramuan yang telah disediakan sedangkan pada ilmu medis ibu bersalin masih menganggap bahwa pemeriksaan kesehatan itu perlu dilakukan, Akan tetapi sikap ibu bersalin yang ditunjukkan adalah sesuatu yang keliru dan sangat bertentangan dengan program kemitraan Bidan dukun. Tentunya dalam hal ini peran serta dukun untuk mengontrol dan memantau ibu-ibu hamil yang telah memasuki usia kandungan lahiran agar segera melaporkan kepada petugas kesehhatan terdekat.

Hal ini sejalan dengan penelitian hasil penelitian Eyando di Tangerang tahun diketahhui bahwa salah satu alasan ibu menggunakan jasa paraji/dukun untuk periksa kehamilan dan persalinan adalah karena dukun memiliki kemampuan urut yang tidak dimiliki oleh Bidan. ${ }^{4}$

Metode urut/pijat telah dikenal sejak lama dan bertujuan utama untuk melancarkan peredaran darah dan merilekskan otot-otot tubuh, sehingga orang yang diurut akan merasakan tubuhnya menjadi segar dan keletihan akan hilang. Metode ini baik untuk semua jenis umur termasuk bayi, bahkan penelitian T.Field dan Scafidi dari Universitas Miami menunjukkan bayi premature yang diurut $3 \times 5$ menit selama 10 hari mengalami kenaikan berat badan 20-47\%. Akan tetapi berbeda kasus pada bayi dan ibu hamil, ahli kandungan berpendapat bahwa ibu hamil tidak boleh diurut atau dipijat pada bagian perut, karena secara fisiologis janin pada awal kehamilan selalu mengadakan rotasi sehingga posisi kepala tidak selalu dibawah. Hal ini adalah normal karena jumlah massa cairan yang lebih besar dibanding berat janin. ${ }^{6}$

Hal yang berbeda yang ditunjukkan oleh wawancara kepada informan triangulasi Bidan Koordinator Puskesmas bahwasanya apa yang dilakukan oleh masyarakat/ibu bersalin tersebut merupakan sesuatu sikap yang sangat salah dan keliru. Hasil kutipan wawancara kepada informan triangulasi Bidan Koordinator dapat dilihat dibawah

"Kalo menurut saya persalinan yang dibantu dengan dukun kurang efektif. Kenapa karena teralu banyak resiko yang bisa muncul ketika persalinan di tolong oleh dukun, hanya berdasarkan pengalaman bukan ilmu"

"Pada dasarnya ilmu yang kita punya sangat jauh berbeda dan mereka tidak memahami

Puskesmas Ueesi merupakan fasilitas kesehatan tingkat pertama yang berada di dataran tinggi, sekalipun puskesmas tersebut cukup sulit untuk akses dari segi transportasi darat namun dari segi transfer knowledge pihak Puskesmas terus berupaya untuk memenuhi kebutuhan masyarakat tersebut. Terutama dalam hal ketimpangan antara pelayanan medis dan tradisional.. Sebagaimana dengan kutipan wawancara berikut :

"Sebenarnya sangat bagus karena dukun bukan untuk menolong persalinan tapi sebatas membantu seperlunya saja, kalo nda diperlu ya cukup menonton"

(IT.BK)

"Itu yang bermitra antara saya dengan bu Bidan, terkahir terakhir ini pi baru da jalan waktu dulu dulu nda ada itu, ma semoga mi kasian da bagus itu supaya bisa diperbaiki lagi toh"

(IT.DB)

Sejalan dengan program kemitraan dukun dan Bidan bahwasanya dukun bersalin mengakui bahwa apa yang dilakukannya saat ini sebenarnya keliru namun dukun bersalin 
tidak ada pilihan lain selain menolong anak manusia dan semua yang dilakukan sematamata hanya untuk membantu dan tidak ada unsur niat lain dan mendukung program yang telah ditetapkan oleh Pemerintah sehingga dukun bersalin juga melaksanakan tugasnya sesuai dengan kesepakatan yang dibangun melalui kemitraan dukun dan Bidan. Sebagaimana kutipan wawancara berikut :

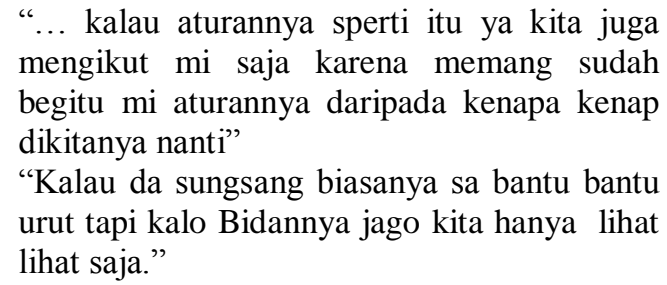

(IT.DB)

Peneliti melakukan wawancara kepada informan triangulasi kepada Bidan Koordinator Puskesmas. Dalam hal ini pihak Puskesmas Ueesi mengakui dan meyakini masih adanya praktik dukun bersalin di wilayah kerja Puskesmas Ueesi, akan tetapi, seiring dengan semakin baiknya peraturan perundang undangan yang dibuat oleh Pemerintah Pusat dapat membuat ruang sempit bagi praktik-praktik dukun bersalin, terlebih lagi dengan jejaring dan komunikasi yang dibangun bersama aparat Desa, Tokoh Masyarakat/agama dan pihak keluarga agar kepada ibu-ibu bersalin senantiasa memanfaatkan jasa tenaga kesehatan. Kader kesehatan pun tidak luput dari peran sertanya untuk menyampaikan informasinya terkait adanya ibu yang menggunakan jasa non tenaga kesehatan,Terlebih saat ini Pemerintah memalui program BOK-Jampersal diharapkan mampu menekan AKI dan AKB di daerah dengan mengalokasikan anggaran persalinan untuk ibu-ibu bersalin sehingga tidak ada lagi alasan bagi Pemerintah Daerah untuk tidak meningkatkan derajat kesehatan masyarakat di wilayahnya. Banyaknya kegiatan yang bersumber dari BOK Jampersal salah satunya adalah pemanfaatan Rumah Tunggu Kelahiran (RTK). Melalui program ini masyarakat memiliki alternative lain dengan menggunakan fasilitas yang disediakan oleh Puskesmas dimana sumber pembiayaan operasional seluruhnya ditangggung melalui anggaran BOKJampersal.

c. Kepercayaan

Kepercayaan masyarakat dan keyakinannya terhadap pemanfaatan jasa non tenaga kesehatan turut memberikan pengaruh yang buruk pada upaya peningkatan status derajat kesehatan masyarakat. Adapun kutipan wawancara kepada informan utama sebagai berikut :

"Na kita baku tau ji pak siapa orang tolong kita.."

"Sudah terbiasa mi tangannya pak"

Hal yang sama dikemukakan oleh informan triangulasi yang memandang bahwa tradisi yang berkembang di masyarakat adalah hal yang lumrah dan Pemerintah dalam hal ini Puskesmas Ueesi tidak memiliki kewenangan untuk mengintervensi sebuah budaya sosial yang berkembang di Masyarakat. Adapun kutipan wawancara bersama informan triangulasi sebagai berikut:

"Kalau masalah tradisi sudah pasti masih ada, beberapa masyarakat tetapi kami mencoba perlahan untuk menghilangkan"

(IT.BK)

Berdasarkan keterangan beberapa informan utama diatas maka dapat disimpulkan bahwa informan begitu yakin dengan kemampuanyang dimiliki oleh dukun bersalin, hal ini dikarenakan intensitas $\mathrm{ibu}$ bersalin dalam menggunakan jasa dukun bersalin terlebih lagi selama memanfaatkan dukun bersalin informan tidak mengalami masalah kesehatan dengan kata lain selama ini wajar-wajar saja dalam pemanfaatannya.Menurut foster dan Anderson dalam system medis yang merupakan bagian dari system sosial 
memiliki beberapa ciri antara lain, kepemilikannya melalui proses belajar berdasarkan pengalaman, selain itu dimungkinkan adanya variasi dalam satu kelompok masyarakat yang disebabkan adanya kontak dengan lingkungan budaya lain yang memiliki system medis yang berbeda, selain itu system medis juga dapat berubah. Teori perubahan masyarakat lanjut menurut Foster dapat berjalan sedikit demi sedikit dan setahap demi setahap, tetapi dapat juga mengalami kemunduran atau jalan ditempat. $^{7}$

2. Faktor Enabling

a. Akses

Salah satu ciri khas pelayanan yang baik adalah mampu untuk dijangkau baik itu dari segi jarak, biaya dan ketersedian fasilitas sarana dan prasarana. Sama halnya dengan fasilitas pelayanan lainnya seperti fasilitas dukun bersalin. Dalam hal ini peneliti melihat bahwa aktifitas "jemput bola" yang dimiliki dukun bersalin merupakan salah satu modal utama sehingga maraknya pelayanan pertolongan persalinan oleh dukun bersalin. Berikut kutipan wawancara informan utama dari segi jarak ke fasilitas dukun bersalin:

$$
\begin{aligned}
& \text { "Nda jauh rumahnya.." } \\
& \text { "Rumahnya nda jauh jauh.." } \\
& \text { "Biasanya dia datang naik motor pak.." }
\end{aligned}
$$

(IU.R4)

Selain jarak yang relatif dekat sehingga mudah di jangkau oleh ibu bersalin, kemudahan sarana transportasi pun turut menjadi salah satu faktor yang menunjang pemanfaatan layanan persalinan dukun bersalin. Selain itu masayarakat pula pernah menggunakan sarana Handy Talky (HT) dan aktifitas "jemput bola" tersebut merupakan hal yang lumrah yang dilakukan oleh dukun bersalin. Berikut kutipan wawancara kepada informan triangulasi berikut:

"Kalo kesana biasa kita jalan jalan saja atau nda nae motor.."

"Pernah dlu pake HT tapi beh jemput naik motor saja.."
Hal yang sama dengan informasi dari informan triangulasi yang diperoleh berdasarkan hasil wawancara. Begitu luasnya wilayah kerja Puskesmas Ueesi berdampak kepada kemampuan tenaga kesehatan untuk mengakses masyarakat cukup sulit terlebih dengan terbatasnya sumber daya manusia (SDM) / tenaga kesehatan yang mengabdi di Desa. Berikut kutipan wawancara :

"Tenaga Bidan kami disini masih kurang, kami menggunakan system kewilayahan dimana 1 orang Bidan rangkap 2 desa"

(IT.BK)

Pemerintah Kecamatan Ueesi saat ini bersyukur dengan adanya penempatan Bidan Desa yang di biayai oleh Dinas Tenaga Kerja dan Transmigrasi (Nakertrans) Kabupaten Kolaka Timur. Setelah Peneliti melakukan telaah dokumen Puskesmas, diperoleh informasi bahwa Pustu yang ada saat ini hanya berada di Desa Porabua itu pun dalam Kondisi Rusak Berat, dan 3 (tiga) Poskesdes yang berada di Wilayah Kerja Puskesmas Ueesi juga dalam kondisi rusak berat dengan kata lain hampir tidak adanya fasilitas pelayanan kesehatan di Puskesmas Ueesi kecuali Gedung Puskesmas itu sendiri dan Rumah Tunggu Kelahiran (RTK) dan itupun masih menggunakan rumah warga dan terletak tidak jauh dari Puskesmas induk. Selanjutnya peneliti melakukan kroscek untuk menggalli informasi seputar pembangunan atau rehabilitasi bangunan fasilitas kesehatan di Kecamatan Ueesi ke Dinas Kesehatan Kabupaten Kolaka Timur (Subag Umum dan Kepegawaian) diperolehnya informasi bahwa pada Tahun anggaran 2016, Pemerintah dalam hal ini Dinas Kesehatan mengalokasikan anggaran Kesehatan fisik pada postur APBD untuk Pembangunan rumah dinas 
tenaga kesehatan Puskesmas Ueesi, Dinas Kesehatan dalam hal ini berasumsi bahwa perlu dibangunnya fasilitas rumah dinas tenaga kesehatan agar tidak adanya alasan bagi tenaga kesehatan untuk tidak memiliki tempat tinggal yang layak dan tetap untuk selanjutnya mampu melayani masyarakat tanpa harus keluar masuk kecamatan Ueesi, sehingga diharapkan tenaga kesehatan untuk stay dan menetap di Puskesmas Ueesi. Terkait dengan ketersediaan tenaga kesehatan bahkan Tahun 2016 pula Dinas Kesehatan telah mengirimkan 1 (satu) orang tenaga PNS dokter umum untuk di tempatkan di Puskesmas Ueesi membantu masyarakat meningkatkan derajat kesehatan yang memang saat ini diakui masih cukup tertinggal dan lanjut menurut keterangan pihak Dinas Kesehatan dengan adanya pengangkatan CPNS dari formasi Bidan PTT diharapkan mampu mengcover pelayanan kesehatan di Kecamatan Ueesi.

\section{b. Biaya Persalinan}

Jumlah dan atau kerelaan masyarakat dalam menilai, balas jasa terhadap pelayanan non tenaga kesehatan biasanya dalam bentuk nilai rupiah. Biaya persalinan ini pula sering kali masyarakat mengartikan dalam bentu rupiah, nilai tukar terkadang hanya dengan menggunakan hasil pertanian akan tetapi hal tersebut sudah lama ditinggalkan jauh oleh penduduk sekitar, bilamana ibu bersalin tidak memiliki biaya yang cukup tentunya dukun bersalin tidak akan memaksa untuk diberikan biaya karena pada dasarnya kerelaan dukun bersalin merupakan modal utama dalam memberikan pertolongan ke ibu bersalin dengan kata lain tidak mematok tarif dalam memberikan pelayanan. Saat ini ibu bersalin mampu menjangkau biaya persalinan oleh dukun bersalin karena memang sesuai dengan pendapatan ibu sehari-harinya. Sebagaimana kutipan wawancara informan utama sebagai berikut:

"Nda sampe mahal mahal bagaimana ji kalo sama ina.."

“..Owhh bisa ji pak syukurnya nda
Terkait dengan program Jampersal yang dimiliki oleh Pemerintah Pusat bahwa saat ini program tersebut belum menyentuh secara langsung kepada ibu bersalin khusunya ibu bersalin yang berada pada wilayah dataran tinggi, tapi pemahaman sepihak yang dimiliki oleh ibu berslin di wilayah dataran rendah membuat makna program jampersal ini agak sedikit berubah makna. hal ini dapat dilihat pada kutipan wawancara infoman utama sebagai berikut :

"Dulu ada kita dijelaskan tapi saya lupa mi.."

(IU.T2)

"Bisa juga kita pakai, bagus memang tp itu mi juga jarang dipakai.."

(IU.R4)

Sejalan dengan biaya persalinan yang diberikan oleh ibu bersalin. Peneliti melakukan wawancara kepada informan triangulasi Bidan Koordinator dan dukun bersalin bahwasanya tarif dalam pelayanan persalinan non tenaga kesehatan tidak ada, sekalipun ada biasanya ibu bersalin dalam memberikan uang hanya semata-mata ala kadarnya dan secukupnya saja. Berbeda halnya dalam program kemitraan, Puskesmas Ueesi membantu dalam urusan transportasi Dukun bersalin sebesar Rp. $50.000,-$. Namun ada pelayanan yang dimiliki oleh dukun bersalin seperti memandikan dan mengurut bayi biasanya dukun bersalin mematok tarif sekitar Rp. 350.000 ,- untuk perawatan bayi dan ibu selama kurun waktu 1 (satu) minggu untuk pagi dan sore pelayanan. Sebagaimana kutipan wawancara berikut ini :

"Kalau untuk biaya itu sebenarnya tergantung dari ibu bersalinnya tapi kalau kemitraan kami kasih dukunnya itu 50.000,-.."

\section{(IT.BK)}

"Kalau mau melahirkan yang utama kasian anaknya sama mamanya mi dlu,maa urusan biayabiar da tidak kasih kita mengerti ji kasian namanya saling tolong kalau adapun di kasih berapa berapanya saja sa tidak permasalahkan ji, tapi kalau kasih mandi sampe urut mamanya biasanya 350rb itu pak, untuk transpor saja kasian.."

(IT.DB 
oleh Pemerintah Pusat sudah mulai terpisah dari segi pembiayaan kepada Bidan dan Dukun bersalin karena dalam Jampersal semua dilakukan secara professional melalui pengelolaan dan pemanfaatan rumah dukun dan hingga saat ini program tersebut berjalan dengan lancar, namun dukun bersalin kurang mengetahui Program Jampersal dari segi pembiayan atau anggaran sehingga dukun bersalin tetappada koridornya dengan semua pelayanan gratis yang diberikan, sebagaimana kutipan wawancara berikut :

\section{"Jampersal diwilayah kerja kami sangat luar biasa, karena program ini sudah menggratiskan semua jenis pelayanan persalinan termasuk Rumah tunggu kelahiran itu sendiri." \\ "Iye pernah sa dengar itu jampersal jampersal tapi sa nda tau bagaimana modelnya, katanya gratis, tapi saya juga gratis gratis ji sa nda minta - minta juga uangnya orang kasian." \\ (IT.DB)}

Berdasarkan beberapa hasil wawancara diatas maka dapat disimpulkan bahwa dari segi pembiayaan persalinan baik itu pihak Puskesmas dan Dukun bersalin sama-sama menggratiskan biaya persalinan namun dengan metode yang berbeda. Terkait dengan program Jampersal, masih adanya ibu bersalin yang kurang bahkan adanya yang tidak mengetahui tentang program tersebut. Bahkan ada beberapa informan yang mengetahui namun hanya gambaran secara kecilnya sehingga masyarakat kurang menggunakan program tersebut dikarenakan masyarakat telah jenuh dengan program jaminan-jaminan yang dimiliki oleh Pemerintah dikarenakan proses admintrasi yang ribet dan berbelit membuat masyarakat beralih ke pembiayaan lain selagi tidak memberatkan. Seandainya dukun bersalin dibekali pemahaman terkait Program ini, sekiranya mampu mengalihkan pasiennya untuk memanfaatkan program Jampersal dikarenakan saat ini program kemitraan dukun dan Bidan sudah berjalan dengan baik dan diharapkan Jampersal pula memiliki keharmonisan dan koordinasi yang sama dengan antara dukun dan Bidan guna bersama-sama meningkatkan derjajat kesehatan masyarakat.

3. Faktor Enabling

Dukungan Keluarga/Toma

Hampir semua informan utama mengatakan bahwa persalinan dengan dukun bersalin bukan menjadi masalah bagi mereka selama ibu dan bayi yang dilahirkan dalam kondisi sehat. Sebagaimana kutipan wawancara berikut ini :

"Mertua cukup jauh dari sini jadi bapaknya ji biasa sa Tanya nda papa ji.."

"Mengikut ji kalo orang disini.."

Dalam kurun waktu beberapa bulan terakhir ini, baik itu Tokoh Masyarakat, agama dan adat serta ketua karang taruna bersama-sama dengan Pemerintah kecamatan untuk berkomitmen dalam rangka meningkatkan derajat hidup kesehatan masyarakat melalui program gerakan masyarakat dnegan pendekatan keluarga. Sasaran utama pada kesepakatan tersebut adalah ibu hamil dan ibu bersalin. Komitmen yang dibangun para aparat kecamatan tersebut agar tidak adanya persalinan yang ditolong oleh dukun bersalin dan bersama-sama membantu ibu bersalin di fasilitas-fasilitas kesehatan yang disediakan oleh Pemerintah.Sebagaimana kutipan wawancara informan utama dibawah ini :

"Ada juga orang yang pake dukun pak tapi itu pak dusun da pernah larang kita"

"Biasa juga orang sini pakai dukun. Pa Desa juga mulai mi da kasihtau kita kalo nda boleh."

(IU.R4)

Sejalan dengan keterangan beberapa informan utama diatas, peneliti 
melakukan wawancara kepada informan triangulasi yakni dukun bersalin dan Bidan Koordinator diperolehnya informasi bahwa saat ini dengan era BOK - Jampersal dengan begitu cukup tingginya anggaran kesehatan, Pemerintah menyediakan fasilitasfasilitas dalam rangka meneakn AKI AKB di daerah-daerah terpencil. Hasil wawancara pada informan triangulasi dapat dilihat pada kutipan wawancara berikut :

"Kebetulan secara langsung tokoh masyarakat mendukung program dari kami karena mereka melihat bahwasanya banyaknya masalah persalinan itu disebabkan oleh dukun bersalin.."

(IT.BK)

"Kalau dulu mau di apa pak, kondisi hae ma sekarang kalo di tau pasti mi kita di marahi dulu baru nda tau mau di apakan..'

"Kita ini pak sudah tidak boleh lagi tolong orang, karena sekarang ada katanya aturannya kita nda mau juga dipenjara kalo ada apa-apa.."

(IT.DB)

Peneliti selanjutnya melakukan telaah profil Puskesmas dimana adanya berita acara serta dokumentasi hasil pertemuan warga dan pihak Puskesmas terkait kesepakatan dukungan tokoh masyarakat untuk memantu ibu bersalin agar tidak menggunakan jasa dukun dalam persalinan dan melaporkan hal-hal yang terkaittindakan praktik berslaian. Maka dapat disimpulkan bahwasanya tokoh masyarakat sangat mendukung program yang dicetuskan oleh Pemerintah melalui Puskesmas Ueesi guna peningkatan derajat kesehatan masyarakat.

\section{KESIMPULAN}

Pemanfaatan pelayanan persalinan pada faktor Predisposing (predisposisi) oleh ibu bersalin ditinjau dari aspek pengetahuan kurang memahami tentang jenis persalinan yang aman. Pada aspek sikap ibu bersalin dalam memanfaatkan persalinan non tenaga kesehatan dikarenakan di wilayah desa khusunya terpencil tidak memiliki fasilitas kesehatan yang memadai, dukun bersalin telah berakar di wilayah kerja Puskesmas ueeesi.

Pemanfaatan pelayanan persalinan pada faktor Enabling (pemungkin) oleh ibu bersalin ditinjau dari aspek akses ibu bersalin, praktik dukun bersalin berkembang dikarenakan dukun bersalin selalu ada pada saat dibutuhkan. Sedangkan pada aspek biaya persalinan ibu menjangkau seluruh biaya yang diperlukan saat persalinan bersama dukun bersalin.

Pemanfaatan pelayanan persalinan pada faktor Reinforcing (penguat) oleh ibu bersalin ditinjau dari aspek dukungan keluarga/tokoh masyarakat terhadap ibu bersalin dapat disimpulkan bahwa masih adanya beberapa keluarga ibu bersalin yang mendukung persalinan ditolong oleh dukun bersalin namun para unsur terkait berkomitmen membantu dan membawa ibu-ibu bersalin ke fasilitas kesehatan yang telah disediakan, tidak memperkenankan dukun bersalin untuk melakukan pertolongan persalinan.

Disarankan kepada puskesmas untuk melakukan supervisi secara aktif untuk dapat melihat sejauhmana pencapaian tugas para tenaga kesehatan (Bidan) Desa guna mengetahui permasalahan teknis dan membantu dalam menemukan solusi / jalan keluarnya.

\section{Daftar Pustaka}

1. Dinas Kesehatan Kabupaten Kolaka Timur. Profil Dinas Kesehatan Kabupaten Kolaka Timur 2016. Kolaka Timur.

2. Notoatmodjo. Prilaku Kesehatan. Jakarta; Rineka Cipta. 2005

3. Ummpact. Laporan Hasil Penelitian Immpact di Indonesia. Jakarta: Pustaka FKM UI. 2007

4. Eryando T. Alasan Pemeriksaan Kehamilan dan Pemilihan Penolong Persalinan. Jurnal Administrasi Kebijakan Kesehatan. Volume 6 Edisi Januari 2008 
5. Roesli, U. Pedoman Pijat Bayi. Majalah Kesehatan Edisi November. 2010

6. Prawirohardjo. Ilmu Kebidanan. Jakarta: YSP. 2007

7. Joyomartono M. Pengantar Antropologi Kesehatan. Semarang : UNNES Press. 2004 